\title{
Social aspects of sustainable supply chains: unveiling potential relationships in the Brazilian context
}

\author{
Charbel Jose Chiappetta Jabbour ${ }^{1}$ - Rafael Caliani Janeiro ${ }^{2}$. \\ Ana Beatriz Lopes de Sousa Jabbour ${ }^{1}$ • Jose Alcides Gobbo Junior ${ }^{2}$. \\ Manoel Henrique Salgado ${ }^{2}$. Daniel Jugend ${ }^{2}$
}

(C) Springer Science+Business Media, LLC 2017

\begin{abstract}
Drawing on theoretical assumptions from equity theory applied to exchange situations between businesses, and justice concepts applied to supply chains, this work has the original objective of discussing the level of implementation of social aspects of operations management by focusing on inter-organizational justice in Brazilian's supply chains. In this context, this research presents a quantitative survey study, in which managers of Brazilian companies answered a questionnaire on their perceptions of levels of adoption of practices/initiatives for justice in supply chains. The results indicate that: (a) most of the analyzed practices have potential to be adopted in a more intense way, revealing potential actions that managers should take in order to promote social justice over the supply chain; (b) there are many positive correlations among the analyzed practices, which may suggest potential relationships, revealing practices that could have a joint implementation. Other results, implications, and research limitations were equally presented by taking into account particularities of Brazilian national culture.
\end{abstract}

Charbel Jose Chiappetta Jabbour

c.chiappetta-jabbour@montpellier-bs.com

Rafael Caliani Janeiro

rafaelcj_getulina@hotmail.com

Ana Beatriz Lopes de Sousa Jabbour

ablsjabbour@gmail.com

Jose Alcides Gobbo Junior

gobbo@feb.unesp.br

Manoel Henrique Salgado

Henri@feb.unesp.br

Daniel Jugend

daniel@ feb.unesp.br

1 Montpellier Business School, Montpellier Research in Management, 2300, avenue des Moulins, 34185 Montpellier, Cédex 4, France

2 UNESP - Sao Paulo State University, Av Eng Edmundo Carrijo Coube 14-01, Bauru-Sao Paulo Zip: 17033360, Brazil 
Keywords Organizational justice $\cdot$ Sustainability $\cdot$ Supply chain management $\cdot$ Sustainable operations $\cdot$ Sustainable production and consumption

\section{Introduction}

This work is anchored in the theoretical assumptions of equity theory (Huppertz et al. 1978; Messick and Cook 1983; Scheer et al. 2003) — that in exchange business situations fair practices can lead to trust between stakeholders (Jap 2001; Found 2013) —and that concepts of equity theory can help to understand the complexity of adopting advanced operations practices (Found 2013) such as social aspects in supply chain management. This research additionally recognizes that national culture can influence the way businesses develop exchange situations (Griffith et al. 2006b; Dant et al. 2008; Ketkar et al. 2012; Ueltschy et al. 2007), with implications for equity, social practices and sustainability spreading across supply chains to a greater or lesser level. These theoretical lenses are key to pushing sustainable operations theory and practice forward.

Sustainable operations management and sustainable supply chain management (SSCM) (Mani et al. 2016a, b; Walker et al. 2014; Gunasekaran et al. 2014) are becoming subjects of growing interest, for both researchers in the operations management field (Gunasekaran and Irani 2014) and practitioners (Govindan et al. 2014). Academic interest pertaining to dealing with sustainability in supply chains has increased. For example, considering only the environmental dimension of sustainability in supply chains, Gurtu et al. (2015) showed that the intensity of research in this area, measured through keywords, has more than tripled in the recent past.

According to Ageron et al. (2012), more sustainable supply chains imply the pursuit of organizational sustainability (considering the economic, environmental, and social dimensions) beyond the boundaries of a single organization, involving all of the players in a given chain supply (consumers, focal firm, and suppliers).

In the past decade, a more sustainable management of the supply chains has been a topic dominated by studies on the "environmental" dimension of sustainability, giving rise to green supply chain management (GSCM). Although studies on GSCM have significantly advanced the understanding of the limits and possibilities of SSCM, there is still a significant shortfall in the state-of-the-art literature regarding the subject of the "social" dimension of SCCM. The state-of-the-art literature reveals greater emphasis on the environmental dimension of sustainability in a supply chain, while the social dimension has received limited attention (Ahi and Searcy 2015a, c; Sarkis 2012), creating difficulty in measuring advances in sustainability practice (Davidson 2011). The literature on sustainable supply chains has paid less attention to the social dimension of the debate (Mani et al. 2016a, b; Lu et al. 2012). In general, firms have long faced challenges when pursuing social sustainability. In this context, Segovia-SanJuan et al. (2015) found that some practices of social responsibility tend to be more concerned with organizational reputation than the commitment to their own employees.

Within the context of searching for more socially responsible management of supply chains, the discussion of "inter-organizational justice" across supply chains stands out. Interest in this topic is not just academic, but also relevant to consumers, who have been increasingly interested in social issues (Huq et al. 2014). To date, the pioneering work of Narasimhan et al. (2013) has presented empirical evidence regarding the understanding of justice in supply chains that seek to be more sustainable. Justice in supply chains can be understood in three dimensions: (1) procedural justice; (2) distributive justice; and (3) inter- 
actional justice. According to Narasimhan et al. (2013), these three dimensions of justice in supply chains can be measured by means of practices for inter-organizational justice adopted by companies. These authors suggested that higher levels of adoption of practices for justice can contribute significantly to improving firms' performance. Thus, the "justice" aspect across SCCM is relevant.

In general, there is little research on the "social" dimension of supply chains (Ahi and Searcy 2015a; Mani et al. 2016b), and this gap is even larger when the focus of the analysis is on "justice." The works of Griffith et al. (2006a), Liu et al. (2012), and Narasimhan et al. (2013) are the most relevant and all prove the positive effects of the adoption of practices for justice in supply chains. However, even less is known about the subject of justice in the supply chains of emerging economies, with the exception of the findings by Liu et al. (2012), who analyzed Chinese companies. Research on sustainable and green supply chain management in South America is scarce (Fahimnia et al. 2015). Therefore, focusing on the context of Brazil, which is the largest economy in Latin America and is part of BRIC (Brazil, Russia, India, and China), the research question to this work is: what is the intensity and correlation among practices for promoting justice in Brazilian companies through the lens of an exploratory survey?

Consequently, the goals of this research are:

- To carry out a survey on the adoption of practices for justice in Brazilian companies based on the framework proposed by Narasimhan et al. (2013);

- To determine the intensity of adoption of practices for justice in Brazilian companies based on Narasimhan et al. (2013); and

- To determine the mutual correlation among the practices in order to verify potential relationships.

We address the survey findings by taking the Brazilian culture into consideration, as this can be considered quite unique and different to mainstream studies in operations management (Jabbour et al. 2016). In the Brazilian organizational context, organizational practicessuch as supply chain management - tend towards a hybrid model (Islam 2012) that adapts international trends (such as European) and national culture, such as the importance of longterm relationships and conflict avoidance (Chu and Wood 2008).

This research can be justified because efforts to establish social equity by supply chains that aim to be more sustainable are increasing (Walker et al. 2014). At the same time, knowledge on the subject has advanced more intensely regarding the environmental aspects of supply chains and less in understanding the social dimension (Ahi and Searcy 2015a). In addition, the state-of-the-art of this subject still requires more research on developing countries in order to properly understand the opportunities and challenges of SSCM worldwide (Pagell and Shevchenko 2014; Hall et al. 2009). Only by having social justice and equity in exchange business situations (Huppertz et al. 1978) will trust and sustainability be fully developed in supply chains. Thus, the main contributions of this work are the following:

- So far, this seems to be the first work to combine topics of social justice in supply chains in Brazil, using Narasimhan et al. (2013) as a reference; and equity theory (Found 2013);

- This research sheds light on the social dimension of sustainable supply chains, responding to calls from the literature (Ahi and Searcy 2015a); and

- The empirical evidence has the potential to uncover interesting implications for improving social aspects of Brazilian supply chains.

The work is organized as follows. After the Introduction section (Sect. 1), a theoretical background is presented (Sect. 2), in order to introduce the theoretical and methodological 
perspectives of this research (Sect. 2.1), social aspects of sustainable supply chains (Sect. 2.2), and a briefing on sustainability in Brazil (Sect. 2.3). Section 4 presents research results, and Sect. 5 presents the discussion and conclusions.

\section{Theoretical background}

\subsection{Explaining the theoretical and methodological perspectives of this research}

The analytical and methodological focus of this research is illustrated in Fig. 1, which shows the concepts of sustainable operations and SSCM are the backdrop for the development of a survey with a sample of Brazilian companies to measure the industrial intensity of adoption of the practices for justice, as suggested by Narasimhan et al. (2013). As there is a myriad of works providing alternative ways for measuring sustainability in supply chains, creating lack of consistent and convergent approach (Ahi and Searcy 2015a), in this work we adopted the perspective of Narasimhan et al. (2013).

Supply chain management (SCM) is a management approach that discusses the fundamental problems of product supply due to the complex flows of demands in a world of constant change and uncertainty (Kopczak and Johnson 2003). It is an approach that gained momentum in the 1990s and 2000s, seeking the integration of processes to effectively ensure the integration between supply and demand (Lambert and Cooper 2000), integrating related companies, under the understanding that companies do not compete in isolation, but instead, competition exists among supply chains. This increasingly competitive environment has implications for equity levels and practices between partners in a supply chain. Equity theory focuses on whether or not the distribution of resources is considered fair for partners (Scheer et al. 2003; Jap 2001; Found 2013; Huppertz et al. 1978). An important theoretical assumption is that fair practices tend to increase the levels of trust, social justice, and sustainability in supply chains.

Sustainable supply chains have gained momentum with the growing debate on sustainable development (Dyllick and Hockerts 2002) and require dynamic integration that achieves the company's economic, social, and environmental goals through a systematic organization of business processes among companies (Carter and Rogers 2008). The advantages of adequate

Sustainable operations in emerging economies: focus on supply chains and equity

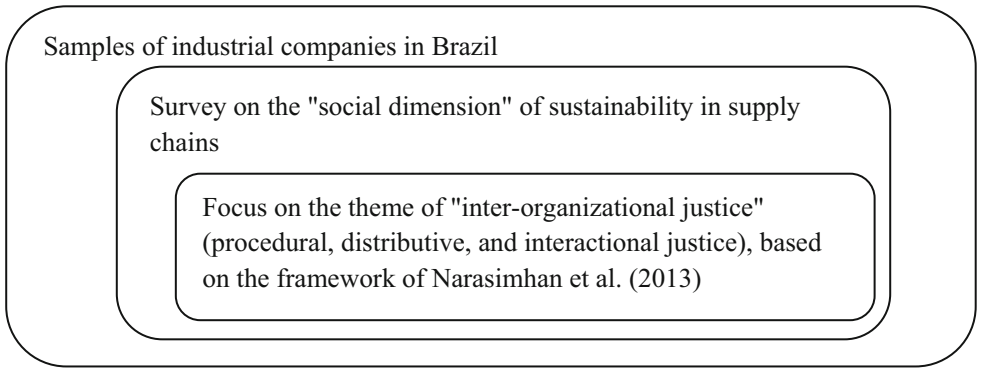

Focus on the theme of "inter-organizational justice" (procedural, distributive, and interactional justice), based on the framework of Narasimhan et al. (2013)

Fig. 1 Conceptual and methodological research's framework 
sustainable supply chain management are the following: an increase in the company's profit and its market share; reduction of risk and environmental impacts; and increase in ecoefficiency without compromising the quality, cost, or characteristics of the product (Azevedo et al. 2011).

The search for truly sustainable supply chains (Pagell and Shevchenko 2014) has been advocated by many scholars and requires a new effort by researchers to understand issues that have so far been insufficiently investigated, such as the social dimension of sustainability in supply chains. The literature on the subject is still scarce, with the exception of some recent examples. Kozlowski et al. (2015) highlights some experiences in the apparel industry when reporting social sustainability initiatives. Some socially oriented approaches and indicators were found, but there is an avenue for further developments in terms of theory and practices. After searching the metrics to measure social issues in supply chains, Ahi and Searcy (2015b) highlight that there are a variety of ways in which safety, welfare, and community-related aspects in supply chains may be measured. However, discussion about social "inter-organizational justice" in supply chains with a focus on emerging economies still has to appear (Sun et al. 2009).

\subsection{SSCM: a focus on "inter-organizational justice” across supply chains}

In the normative sense, justice is the principle of moral right or of goodness. Although there are many interpretations of the concept of justice (Burton 2000), it is usually established with the notion of equity, including with regard to opportunities in society. Although equity is an indelible part of justice, the meaning of justice is much greater (Scherlen and Robinson 2008).

Griffith et al. (2006a), based on a survey of 290 relationships in supply chains, noted that procedural justice and distributive justice have positive outcomes, reducing conflict and improving satisfaction. Liu et al. (2012), based on a survey in China, stated that justice can be an important element in developing effective partnerships that can ultimately improve the performance of companies. However, in times of resource scarcity or contextual difficulties, informational and procedural justice should be strengthened to be more relevant in building partnerships.

The conceptual framework adopted in this work was that of justice as proposed by Narasimhan et al. (2013). According to these authors, justice in supply chains can be categorized into three types: (1) procedural justice; (2) distributive justice; and (3) interactional justice.

Meanwhile, procedural justice can be defined as the degree of equity with which decisions are made with partners in the supply chain (Luo 2007). Lind and Tyler (1988) define procedural justice as considering the degree of equity with which the decisions of individuals or entities are implemented. It differs from distributive justice because procedural justice focuses on the means by which the results appear in the exchanges between partners, whereas distributive justice focuses on the perception of justice associated with the results of the exchange between people. Inspired by Narasimhan et al. (2013) and others works, the following organizational practices/initiatives were used to measure procedural justice:

- Process that guarantee of fair results in partnerships with suppliers;

- Explanation, by companies, of the decision-making criteria to its suppliers; and

- Companies make use of a consistent criteria for decision-making when dealing with the supplier.

- Equity in benefits from the partnership from the point of view of suppliers; 
- Profits for suppliers in the partnerships created;

- Equity in the benefits from the partnership from the point of view of the focal company/buyer and

- Simultaneously seek profits for the company with the partnerships created.

The third dimension of justice - interactional justice - is related to features of social organization, including confidence and knowledge in the relations in supply chains as well as obligations and expectations. These characteristics can facilitate reciprocal actions and spontaneous cooperation. This dimension of justice emphasizes the communication policy, such as the appropriate way for suppliers to complain when they are not satisfied with the contours of the supply chain, or the degree of exchange of relevant information between chain partners (Luo 2007).

According to Colquitt et al. (2001), it is possible to divide this kind of justice into two principles. The first principle, called interpersonal justice, reflects the degree of kindness, dignity, and respect with which people are treated. The second principle focuses on the explanations provided to the people who transmit the information about why the procedures were used in a certain way.

This present work was based on the study conducted by Narasimhan et al. (2013) and used the following practices/initiatives as factors to measure interactional justice:

- Agreement with partners about what information should be shared;

- Efficient resolution of whatever disagreements exist between the company and suppliers;

- Regular exchange of information with suppliers; and

- Disclosure of changes that may affect any of the parties of the partnership.

\subsection{Specificities of the Brazilian context}

A number of researchers have affirmed that Brazil offers a singular context for understanding organizational management in emerging economies (Islam 2012; Hilal 2006; Jabbour et al. 2016). Brazilian culture and its organizations' culture can be understood as mixed-culture, in which organizational practices and concepts derive from digesting European modernism while affirming indigenous cultural sources, resulting in a hybrid co-production of ideas through intercultural encounters (Islam 2012). Particular aspects of Brazilian culture, such as a friendly approach to business partners and conflict avoidance (Chu and Wood 2008) can help to develop long term exchanges that last (Ghisi et al. 2008). According to Pires (2015, p. 6), Brazilian culture has been seen as positive when managing supply chains relations, as “ the multicultural and flexible nature of the Brazilian people[...] seems to be a welcome factor, especially with the growth of the so-called globalization of the economy". As explained by Chu and Wood (2008), Brazil has key characteristics that should be considered when studying the diffusion of organizational trends in the country. As highlighted by Hilal (2006), one of these characteristics is the importance of friendship and relational networking when dealing with business partners. Another trait of Brazilian organizational culture is the use of jokes to indirectly deal with complex and difficult situations, or to deal with more powerful people in business (Duncan and Feisal 1989).

In terms of promoting sustainable consumption and production, the effectiveness of policies is inconsistent and sometimes leads to paradoxical results in Brazil (Echegaray 2013). For example, Brazilians show high levels of concern with environmental issues, when over $90 \%$ consider air pollution, climate change, biodiversity loss, and water availability as very serious problems. The same pool revealed that one in two adults admits being willing to pay more for an ethical product. However, the high level of intentions are not generally translated 
into practice, as less than $20 \%$ of Brazilian consumers tend to follow real ethical consumer action (such as boycotting or rewarding brands and products based on sustainable measures) (Echegaray 2013).

In 2012, Brazil launched an Action Plan for Sustainable Production and Consumption, which contains strategies and targets in order to promote:

- Education for sustainable consumption;

- Sustainable public purchasing;

- An environmental agenda for the public sector;

- Recycling of solid waste;

- Sustainable retail; and

- Sustainable buildings.

The abovementioned strategies and targets should be discussed and implemented by various different stakeholders, such as leaders of manufacturing, services, and banking sectors. Discussing at the local level can improve the adherence to the Plan. However, as noted before, this kind of positive initiative tends to face implementation challenges (Hall et al. 2009).

In order to check the level of adoption of these practices/initiatives for justice in supply chains for a sample of Brazilian companies, a survey was carried out according to the methodological details described below.

\section{Research methodology}

This research is based on a quantitative approach and uses a survey strategy, which includes questions about the perception of organizational managers in Brazilian companies that have ISO9001 regarding the level/intensity of adoption of practices/initiatives for justice in supply chains with which they have a relationship. We selected firms with ISO9001 certification because quality management can be considered a signal of firms' improved performance (O'Neill et al. 2016). Thus, if there are socially oriented practices being adopted by Brazilian firms, they will probably appear among the ISO9001 certified firms. The survey was developed with the support of a website where the survey questionnaire was posted. The survey link was sent by email to more than 500 target respondents, and 40 questionnaires properly filled out were returned. The response rate was not as high as expected, but is aligned with the sample size of other works in Brazil (Thürer et al. 2013). There are difficulties in conducting surveys in Brazil, due to a historical gap that still exists between universities and industry (Dagnino and Velho 1998). The final version of the questionnaire, contained (Table 1): (a) a question to characterize the responding company, and (b) 11 questions about the degree of social interaction with the partners in the supply chain of the company interviewed, based on the variables proposed by Narasimhan et al. (2013). Variable 1 (V1), which refers to the size of the companies, was measured nominally according to Sebrae's (Brazilian Service for Support to Micro and Small Companies) classification for the number of employees in companies (small, medium, and large sizes).

The operationalization of the Justice constructs was as follows: (1) each of the three constructs has three variables/items; (2) variables were classified from V2 to V12 and were measured according to a 5-point Likert intensity scale that ranges from " 1 -not implemented" to "5-fully implemented"; (3) each construct was measured as follows in Table 1; procedural justice was measured by V2-V4; distributive justice was measured by V5-V8; and interactional justice was measured by V9-V12, inspired by the set of practices proposed by Narasimhan et al. (2013). 
Table 1 Constructs and variables used in this study

\begin{tabular}{|c|c|c|}
\hline Construct & Variable (V) & Questions \\
\hline Size of the companies & V1 & $\begin{array}{l}\text { Company size according to Sebrae's classification for number } \\
\text { of employees }\end{array}$ \\
\hline \multirow[t]{3}{*}{ Procedural justice } & $\mathrm{V} 2$ & $\begin{array}{l}\text { Process that guarantee of fair results in partnerships with } \\
\text { suppliers }\end{array}$ \\
\hline & $\mathrm{V} 3$ & $\begin{array}{l}\text { Explanation, by companies, of the criteria for decision-making } \\
\text { in relation to their suppliers }\end{array}$ \\
\hline & V4 & $\begin{array}{l}\text { Use, by companies, of a consistent method for decision-making } \\
\text { when dealing with the supplier }\end{array}$ \\
\hline \multirow[t]{4}{*}{ Distributive justice } & V5 & $\begin{array}{l}\text { Equity in the advantages from the partnership from the point of } \\
\text { view of suppliers }\end{array}$ \\
\hline & V6 & Profits for the supplier in partnerships created \\
\hline & V7 & $\begin{array}{l}\text { Equity in the advantages from the partnership from the point of } \\
\text { view of the focal company/buyer }\end{array}$ \\
\hline & V8 & $\begin{array}{l}\text { Simultaneously seek profits for the company with the } \\
\text { partnerships created }\end{array}$ \\
\hline \multirow[t]{4}{*}{ Interactional justice } & V9 & $\begin{array}{l}\text { Agreement with partners about what information should be } \\
\text { shared }\end{array}$ \\
\hline & V10 & $\begin{array}{l}\text { Efficient resolution of whatever disagreements exist between } \\
\text { the company and suppliers }\end{array}$ \\
\hline & V11 & Regular exchange of information with suppliers \\
\hline & V12 & $\begin{array}{l}\text { Disclosure of changes that may affect any of the parties of the } \\
\text { partnership }\end{array}$ \\
\hline
\end{tabular}

Inspired by Narasimhan et al. (2013)

Checking whether the practices of justice proposed by Narasimhan et al. (2013) have been adopted by Brazilian firms, and the level of correlation among them, is the aim of this work. As a consequence, the collected data was analyzed with the statistical software SPSS 21.0 IBM and was processed using a descriptive statistics test and Pearson's correlation coefficient analysis.

\section{Results}

Regarding V1, the research's sample was based on 35\% of small firms (14 firms), $25 \%$ of medium firms (10 firms), and $40 \%$ of large firms (16 firms). Table 2 shows the descriptive statistics (mean, median, mode, standard deviation, minimum, and maximum) for the answers obtained for V2-V12 (it does not apply to V1 because it is nominal). Mean, median, mode show that most of the practices have been generally adopted by companies with an intensity superior to the middle point of the scale 3. But at the same time, all the variables show "minimum" as 1 , which represents an opportunity for improvement.

Whereas Table 3 shows the frequency distribution of responses over the 5-point scale, from "not implemented" to "totally implemented". It can be noticed that most of the frequencies are concentrated at the highest levels of the scale, indicating adoption of practices for justice in the sample analyzed. Results also show that all of the considered variables have not achieved more than $50 \%$ as "totally implemented". Therefore, there is a significant opportunity to support a number of the surveyed firms to achieve better levels of frequencies classified as "totally implemented". 
Table 2 Descriptive statistics $(\mathrm{N}=40)$

\begin{tabular}{|c|c|c|c|c|c|c|}
\hline Variables & Mean & Median & Mode & $\begin{array}{l}\text { Standard } \\
\text { deviation }\end{array}$ & Minimum & Maximum \\
\hline V1-Company size & $*$ & $*$ & $*$ & $*$ & $*$ & $*$ \\
\hline $\begin{array}{l}\mathrm{V} 2 \text {-Process that guarantee of } \\
\text { fair results in the partnerships } \\
\text { with suppliers }\end{array}$ & 3.350 & 3.5 & 5 & 1.54505 & 1 & 5 \\
\hline $\begin{array}{l}\text { V3-Explanation, by companies, } \\
\text { of the decision-making criteria } \\
\text { to its suppliers }\end{array}$ & 3.525 & 3.5 & 5 & 1.32021 & 1 & 5 \\
\hline $\begin{array}{l}\text { V4-Use, by companies, of a } \\
\text { consistent method for } \\
\text { decision-making when dealing } \\
\text { with the supplier }\end{array}$ & 3.725 & 4.0 & 5 & 1.46738 & 1 & 5 \\
\hline $\begin{array}{l}\text { V5-Equity in the advantages } \\
\text { from the partnership (suppliers) }\end{array}$ & 3.900 & 4.0 & 5 & 1.15025 & 1 & 5 \\
\hline $\begin{array}{l}\text { V6-Profits for the supplier in } \\
\text { partnerships created }\end{array}$ & 3.375 & 3.5 & 5 & 1.42662 & 1 & 5 \\
\hline $\begin{array}{l}\text { V7_Equity in the advantages } \\
\text { from the partnership (focal } \\
\text { company) }\end{array}$ & 3.450 & 4.0 & 5 & 1.41331 & 1 & 5 \\
\hline $\begin{array}{l}\text { V8-Simultaneously seek profits } \\
\text { for the company with the } \\
\text { partnerships created }\end{array}$ & 3.825 & 4.0 & 5 & 1.17424 & 1 & 5 \\
\hline $\begin{array}{l}\text { V9-Agreement with partners } \\
\text { about what information should } \\
\text { be shared }\end{array}$ & 3.600 & 4.0 & 5 & 1.35495 & 1 & 5 \\
\hline $\begin{array}{l}\text { V10_Efficient resolution of } \\
\text { whatever disagreements exist } \\
\text { between the company and } \\
\text { suppliers }\end{array}$ & 3.325 & 4.0 & 4 & 1.28876 & 1 & 5 \\
\hline $\begin{array}{l}\text { V11-Regular exchange of } \\
\text { information with suppliers }\end{array}$ & 3.475 & 4.0 & 4 & 1.19802 & 1 & 5 \\
\hline $\begin{array}{l}\text { V12-Disclosure of changes that } \\
\text { may affect either side of the } \\
\text { partnership }\end{array}$ & 3.475 & 3.0 & 3 & 1.21924 & 1 & 5 \\
\hline
\end{tabular}

* N/A

It may be noted that "V4-Use, by companies, of a consistent basis for decision-making when dealing with the supplier", "V5-Equity in the advantages from the partnership (suppliers)", and "V8-Search for gains for the company simultaneously with the partnerships created" have the highest level of implementation rate in the companies of the sample, as they have more than $60 \%$ as either "totally implemented" or "implemented". Variables "V6Profits for the supplier in partnerships created" and "V10-Efficient resolution of whatever disagreements between the company and suppliers" are the less considered in relation to the level of "implemented" and "totally implemented".

For the bivariate statistical analysis, Pearson's correlation coefficient matrix was used, identifying associations between variables of different sets of justice. Table 4 was prepared according to Hair Jr. et al. (2005).

Table 5 shows the correlations between the variables. According to Hair Jr. et al. (2005), it is desirable that most of the correlations be greater than 0.30 . Only 12 of the 54 correla- 
Table 3 Relative frequency $(\%)$ of responses $(\mathrm{N}=40)$

\begin{tabular}{|c|c|c|c|c|c|}
\hline Variables & $\begin{array}{l}1-\text { Not } \\
\text { implemented }\end{array}$ & 2 & 3 & 4 & $\begin{array}{l}5 \text {-Totally } \\
\text { implemented }\end{array}$ \\
\hline V1-Company size & $*$ & $*$ & $*$ & * & $*$ \\
\hline $\begin{array}{l}\text { V2-Process that guarantee of fair results in } \\
\text { the partnerships with suppliers }\end{array}$ & 20.0 & 10.0 & 20.0 & 15.0 & 35.0 \\
\hline $\begin{array}{l}\text { V3-Explanation, by companies, of the } \\
\text { decision-making criteria to its suppliers }\end{array}$ & 10.0 & 10.0 & 30.0 & 17.5 & 32.5 \\
\hline $\begin{array}{l}\text { V4-Use, by companies, of a consistent } \\
\text { basis for decision-making when dealing } \\
\text { with the supplier }\end{array}$ & 15.0 & 5.0 & 17.5 & 17.5 & 45.0 \\
\hline $\begin{array}{l}\text { V5-Equity in the advantages of the } \\
\text { partnership (suppliers) }\end{array}$ & 5.0 & 5.0 & 25.0 & 25.0 & 40.0 \\
\hline $\begin{array}{l}\text { V6-Profits in the advantages of the } \\
\text { partnership }\end{array}$ & 15.0 & 12.5 & 22.5 & 20.0 & 30.0 \\
\hline $\begin{array}{l}\text { V7-Equity in the advantages of the } \\
\text { partnership (focal company) }\end{array}$ & 15.0 & 10.0 & 20.0 & 25.0 & 30.0 \\
\hline $\begin{array}{l}\text { V8-Simultaneously seek profits for the } \\
\text { company with the partnerships created }\end{array}$ & 5.0 & 10.0 & 17.5 & 32.5 & 35.0 \\
\hline $\begin{array}{l}\text { V9_Agreement with partners about what } \\
\text { information should be shared }\end{array}$ & 10.0 & 12.5 & 20.0 & 22.5 & 35.0 \\
\hline $\begin{array}{l}\text { V10_Efficient resolution of whatever } \\
\text { disagreements exist between the company } \\
\text { and suppliers }\end{array}$ & 15.0 & 7.5 & 25.0 & 35.0 & 17.5 \\
\hline $\begin{array}{l}\text { V11-Regular exchange of information with } \\
\text { suppliers }\end{array}$ & 10.0 & 7.5 & 27.5 & 35.0 & 20.0 \\
\hline $\begin{array}{l}\text { V12-Disclosure of changes that may affect } \\
\text { either side of the partnership }\end{array}$ & 5.0 & 17.5 & 30.0 & 20.0 & 27.5 \\
\hline
\end{tabular}

$*$ N/A

Table 4 Strength of the correlations. Source: Hair Jr. et al. (2005)

\begin{tabular}{ll}
\hline Coefficient variation module & Strength of the association \\
\hline $0.91-1.00$ & Very strong \\
$0.71-0.90$ & Strong \\
$0.41-0.70$ & Moderate \\
$0.21-0.40$ & Weak, but defined \\
$0.01-0.20$ & Weak, almost imperceptible
\end{tabular}

tions are below this value (correlations in bold type); therefore, the study shows potential relationships among variables, although this assumption should be tested by future studies. It is also possible to see that "V3-Explanation, by companies, of the decision-making criteria to their suppliers" to "V4-Use, by companies, of a consistent criterion for decision-making when dealing with the supplier" has the highest observed correlation. This indicates a significant relation between them. "V6-Profits for the supplier in partnerships created" and "V7-Equity in the advantages from the partnership (focal company)" are also strongly correlated. Other correlations that achieved strong coefficients are: "V4-Use, by companies, of a consistent basis for decision-making when dealing with the supplier" to "V2-Process that guarantee of fair results in the partnerships with suppliers", and "V3-Explanation, by 
Table 5 Pearson's correlation coefficients $(\mathrm{N}=40)$

\begin{tabular}{|c|c|c|c|c|c|c|c|c|c|c|c|}
\hline & $\mathrm{V} 2$ & V3 & V4 & V5 & V6 & V7 & V8 & V9 & V10 & V11 & V12 \\
\hline $\mathrm{V} 2$ & 1 & & & & & & & & & & \\
\hline V3 & $.712^{* *}$ & 1 & & & & & & & & & \\
\hline V4 & $.745^{* *}$ & $.844^{* *}$ & 1 & & & & & & & & \\
\hline V5 & $.583^{* *}$ & $.745^{* *}$ & $.697^{* *}$ & 1 & & & & & & & \\
\hline V6 & $.346^{*}$ & $.519^{* *}$ & $.565^{* *}$ & $.414^{* *}$ & 1 & & & & & & \\
\hline V7 & $.454^{* *}$ & $.544^{* *}$ & $.605^{* *}$ & $.502^{* *}$ & $.830^{* *}$ & 1 & & & & & \\
\hline V8 & $.374^{*}$ & $.491^{* *}$ & $.492^{* *}$ & $.480^{* *}$ & $.377^{*}$ & $.543^{* *}$ & 1 & & & & \\
\hline V9 & $.350^{*}$ & $.522^{* *}$ & $.524^{* *}$ & $.451^{* *}$ & 0.279 & $.431^{* *}$ & $.583^{* *}$ & 1 & & & \\
\hline V10 & .250 & $.455^{* *}$ & $.333^{*}$ & $.490^{* *}$ & $.574^{* *}$ & $.551^{* *}$ & .191 & .238 & 1 & & \\
\hline V11 & .185 & $.357^{*}$ & .164 & $.370^{*}$ & .253 & .158 & .152 & .310 & $.628^{* *}$ & 1 & \\
\hline V12 & .277 & $.430 * *$ & $.333^{*}$ & .309 & $.499 * *$ & $.453^{* *}$ & .221 & .087 & $.617^{* *}$ & $.561^{* *}$ & 1 \\
\hline
\end{tabular}

Not applicable to V1

** Correlation is significant at the 0.01 level (2-tailed)

* Correlation is significant at the 0.05 level (2-tailed)

companies, of the decision-making criteria to its suppliers" to "V5-Equity in the advantages of the partnership (suppliers)".

\section{Discussions and conclusions}

Firstly, the research results should be considered in the context of the characteristics of the Brazilian culture (see Chu and Wood 2008; Islam 2012). We highlight that the dimensions of national culture may have influenced the results. Overall, this work aims to contribute to the literature on social aspects of supply chains in emerging economies because:

- It sheds light on social aspects based on inter-organizational justice in supply chains. This new approach is relevant because SSCM has been dominated by discussions on GSCM;

- It adds empirical evidence to a literature that is predominantly conceptual and theoretical;

- It adds empirical evidence from the Brazilian context, an emerging economy, among the ten most relevant economies in the world, and part of the BRIC (Brazil, Russia, India and China) group;

- It suggests that Brazilian companies have started their journey towards socially adequate supply chain management;

- It suggests that Brazilian national culture can be an important context for understanding barriers and motivations of dealing with issues of equity, justice and sustainability in supply chains;

- It confirms that Brazilian firms have the potential to adopt practices proposed by Narasimhan et al. (2013) more intensely; and

- It reveals that potential relationships among the practices in terms of number of observed correlations may have occurred.

This study shows that the leaders of the business companies that were analyzed have mostly adopted the practices of justice. This study also shows that V3 and V4 show the highest correlation, followed by V7 and V8. Thus, the relation V3-V4 suggests, for example, that companies should be clear about suppliers' selection criteria by adopting in-depth explana- 
tions. This indicates the interdependence of these actions in a company, which means that variables of strong relationships should be implemented together.

Due to the fact that research results show the opportunity for adopting practices suggested by Narasimhan et al. (2013) more intensely, the following recommendations are made:

- For managers, there is an opportunity for improving social aspects of supply chains, in order to have a differentiation in the market;

- For managers, knowing the potential relationship between practices can facilitate their adoption;

- For industrial policymakers, social justice in supply chains should be considered within the Brazilian governmental plans for promoting sustainable production and consumption;

- For universities, there is an opportunity to offer training, courses, and executive education in the field of social justice in supply chains. Thus, higher education institutions will be able to contribute even more to the advancement of sustainable development; and

- It would be necessary for academics who teach sustainable supply chains to add content about justice in supply chains into their teaching plans.

This research has limitations, such as being restricted to Brazil and not allowing more sophisticate statistic application. Additionally, this research did not adopt 'industrial sector' as a control variable, which could be remedied in future research. Other control variables, such as debt ratio, level of internationalisation and age, can also be adopted in further research models. We might also highlight the potential bias effect because the research results are based on managers' perceptions, only using a single respondent approach, which can be complemented by more sophisticated data collection procedures. Social desirability bias has become a concern in sustainability studies, as the respondents try to perform as they believe interviewers expect. Under this circumstance, less accurate responses than were desirable could have been be obtained (Roxas and Lindsay 2012).

Future research may explore the human (Ehnert 2009; Paillé et al. 2014) and technical barriers when adopting inter-organizational supply chain justice. Future works may also offer a structured literature review (Touboulic and Walker 2015) on inter-organizational supply chain justice, mainly in developing economies (Ghalib and Agupusi 2014). Additionally, further research on social justice in supply chains can consider the perspective of different emerging economies, in order to add more evidence to the current literature (Mani et al. 2016a, b; Lu et al. 2012). In addition, in-depth qualitative studies could be equally relevant. Furthermore, cross-country studies (Griffith et al. 2006b) would allow an exploration of the role played by national cultures in promoting equity and social justice in supply chains across the globe. Finally, benchmarking sustainable performance of companies (Dubey et al. 2017) by taking in account the social dimension can also push the knowledge on the topic further.

Acknowledgements Funding was provided by Conselho Nacional de Desenvolvimento Científico e Tecnológico (Grant PIBIC).

\section{References}

Ageron, B., Gunasekaran, A., \& Spalanzani, A. (2012). Sustainable supply management: An empirical study. International Journal of Production Economics, 140(1), 168-182.

Ahi, P., \& Searcy, C. (2015a). An analysis of metrics used to measure performance in green and sustainable supply chains. Journal of Cleaner Production, 86, 360-377.

Ahi, P., \& Searcy, C. (2015b). Measuring social issues in sustainable supply chains. Measuring Business Excellence, 19(1), 33-45. 
Ahi, P., \& Searcy, C. (2015c). Assessing sustainability in the supply chain: A triple bottom line approach. Applied Mathematical Modelling, 39(10/11), 2882-2896.

Azevedo, S. G., Carvalho, H., \& Cruz, M. V. (2011). The influence of green practices on supply chain performance: A case study approach. Transportation Research Part E, 47, 850-871.

Burton, E. (2000). The compact city: Just or just compact? A preliminary analysis. Urban Studies, 37(11), 1969-2006.

Carter, C. R., \& Rogers, D. S. (2008). A framework of sustainable supply chain management: moving toward new theory. International Journal of Physical Distribution and Logistics Management, 38(5), 360-387.

Chu, R. A., \& Wood, T, Jr. (2008). Brazilian cultural organization in post-globalization: Global or local? Revista de Administração Pública, 42(5), 969-91.

Colquitt, J. A., Wesson, M. J., Porter, C. O. L. H., Conlon, D. E., \& Ng, K. Y. (2001). Justice at the millennium: A meta-analytic review of 25 years of organizational justice research. Journal of Applied Psychology, 86(3), 425-445.

Dagnino, R., \& Velho, L. (1998). University-industry-government relations on the periphery: The University of Campinas, Brazil. Minerva, 36(3), 229-251.

Dant, R. P., Perrigot, R., \& Cliquet, G. (2008). A cross-cultural comparison of the plural forms in franchise networks: United States, France, and Brazil. Journal of Small Business Management, 46(2), 286-311.

Davidson, K. M. (2011). Reporting systems for sustainability: What are they measuring? Social Indicators Research, 100(2), 351-365.

Dubey, R., Gunasekaran, A., Childe, S. J., Papadopoulos, T., Hazen, B., Giannakis, M., et al. (2017). Examining the effect of external pressures and organizational culture on shaping performance measurement systems (PMS) for sustainability benchmarking: Some empirical findings. International Journal of Production Economics, 193, 63-76.

Duncan, W. J., \& Feisal, J. P. (1989). No laughing matter: Patterns of humor in the workplace. Organizational Dynamics, 17(4), 18-30.

Dyllick, T., \& Hockerts, K. (2002). Beyond the business case for corporate sustainability. Business Strategy and the Environment, 11(2), 130-141.

Echegaray, F. (2013). Sustainability in Brazil: A mixed conundrum. The Guardian, Wednesday 13 March 2013. http://www.theguardian.com/sustainable-business/sustainability-brazil-mixed-conundrum.

Ehnert, I. (2009). Sustainability and human resource management: Reasoning and applications on corporate websites. European Journal of International Management, 3(4), 419-438.

Fahimnia, B., Sarkis, J., \& Davarzani, H. (2015). Green supply chain management: A review and bibliometric analysis. International Journal of Production Economics, 162, 101-114.

Found, P. (2013). Lean supply chains: A behavioral perspective: Examples from packaging supply chains in the FMCG sector. In I. Giannoccaro (Ed.), Behavioral Issues in Operations Management. London: Springer.

Ghalib, A. K., \& Agupusi, P. (2014). Business strategy and corporate responsibility: Perception and practice in the oil industry and the role of non-governmental organisations. Journal of Business Economics and Management, 15(5), 951-963.

Ghisi, F. A., da Silveira, J. A. G., Kristensen, T., Martin, H., \& Lindgreen, A. (2008). Horizontal alliances amongst small retailers in Brazil. British Food Journal, 110(4/5), 514-538.

Govindan, K., Sarkis, J., Jabbour, C. J., Zhu, Q., \& Geng, Y. (2014). Eco-efficiency based green supply chain management: Current status and opportunities. European Journal of Operational Research, 233(2), 293298.

Griffith, D. A., Harvey, M. G., \& Lusch, R. F. (2006a). Social exchange in supply chain relationships: The resulting benefits of procedural and distributive justice. Journal of Operations Management, 24(2), 5-98.

Griffith, D. A., Myers, M. B., \& Harvey, M. G. (2006b). An investigation of national culture's influence on relationship and knowledge resources in interorganizational relationships between Japan and the United States. Journal of International Marketing, 14(3), 1-32.

Gunasekaran, A., \& Irani, Z. (2014). Sustainable operations management: Design, modelling and analysis. Journal of the Operational Research Society, 65(6), 801-805.

Gunasekaran, A., Jabbour, C. J. C., \& de Jabbour, A. B. L. (2014). Managing organizations for sustainable development in emerging countries: An introduction. International Journal of Sustainable Development \& World Ecology, 21, 195-197.

Gurtu, A., Searcy, C., \& Jaber, M. Y. (2015). An analysis of keywords used in the literature on green supply chain management. Management Research Review, 38(2), 166-194.

Hair, J. F, Jr., Anderson, R. E., Tatham, R. L., \& Black, W. C. (2005). Análise multivariada de dados (5th ed.). Porto Alegre: Bookman. 
Hall, J., Matos, S., Severino, L., \& Beltrão, N. (2009). Brazilian biofuels and social exclusion: Established and concentrated ethanol versus emerging and dispersed biodiesel. Journal of Cleaner Production, 17, 77-85.

Hilal, A. V. G. (2006). Brazilian national culture, organizational culture and cultural agreement: Findings from a multinational company. International Journal of Cross Cultural Management, 6(2), 139-167.

Huppertz, J. W., Arenson, S. J., \& Evans, R. H. (1978). An application of equity theory to buyer-seller exchange situations. Journal of Marketing Research, 250-260.

Huq, F. A., Stevenson, M., \& Zorzini, M. (2014). Social sustainability in developing country suppliers: An exploratory study in the readymade garments industry of Bangladesh. International Journal of Operations \& Production Management, 34(5), 610-638.

Islam, G. (2012). Can the subaltern eat? Anthropophagic culture as a Brazilian lens on post-colonial theory. Organization, 19(2), 159-180.

Jabbour, C. J. C., de Sousa Jabbour, A. B. L., Govindan, K., De Freitas, T. P., Soubihia, D. F., Kannan, D., et al. (2016). Barriers to the adoption of green operational practices at Brazilian companies: Effects on green and operational performance. International Journal of Production Research, 54(10), 3042-3058.

Jap, S. D. (2001). Pie sharing' in complex collaboration contexts. Journal of Marketing Research, 38(1), 86-99.

Ketkar, S., Kock, N., Parente, R., \& Verville, J. (2012). The impact of individualism on buyer-supplier relationship norms, trust and market performance: An analysis of data from Brazil and the USA. International Business Review, 21(5), 782-793.

Kopczak, L. R., \& Johnson, M. E. (2003). The supply-chain management effect. MIT Sloan Management Review, 44(3), 27-34.

Kozlowski, A., Searcy, C., \& Bardecki, M. (2015). Corporate sustainability reporting in the apparel industry: An analysis of indicators disclosed. International Journal of Productivity and Performance Management, 64(3), 377-397.

Lambert, D. M., \& Cooper, M. C. (2000). Issues in supply chain management. Industrial Marketing Management, 29(1), 65-83.

Lind, E. A., \& Tyler, T. R. (1988). The social psychology of procedural justice. New York, NY: Plenum Press.

Liu, Y., Huang, Y., Luo, Y., \& Zhao, Y. (2012). How does justice matter in achieving buyer-supplier relationship performance? Journal of Operations Management, 30(5), 355-367.

Lu, R. X., Lee, P. K., \& Cheng, T. C. E. (2012). Socially responsible supplier development: Construct development and measurement validation. International Journal of Production Economics, 140(1), 160-167.

Luo, Y. (2007). The independent and interactive roles of procedural, distributive, and interactional justice in strategic alliances. Academy of Management Journal, 50(3), 644-664.

Mani, V., Agarwal, R., Gunasekaran, A., Papadopoulos, T., Dubey, R., \& Childe, S. J. (2016a). Social sustainability in the supply chain: Construct development and measurement validation. Ecological Indicators, $71,270-279$.

Mani, V., Gunasekaran, A., Papadopoulos, T., Hazen, B., \& Dubey, R. (2016b). Supply chain social sustainability for developing nations: Evidence from India. Resources, Conservation and Recycling, 111, 42-52.

Messick, D., \& Cook, K. (1983). Equity theory: psychological and sociological perspectives. New York, NY: Praeger.

Narasimhan, R., Narayanan, S., \& Srinivasan, R. (2013). An investigation of justice in supply chain relationships and their performance impact. Journal of Operations Management, 31(5), 236-247.

O'Neill, P., Sohal, A., \& Teng, C. W. (2016). Quality management approaches and their impact on firmsx financial performance-An Australian study. International Journal of Production Economics, 171, 381393.

Pagell, M., \& Shevchenko, A. (2014). Why research in sustainable supply chain management should have no future. Journal of Supply Chain Management, 50(1), 44-55.

Paillé, P., Chen, Y., Boiral, O., \& Jin, J. (2014). The impact of human resource management on environmental performance: An employee-level study. Journal of Business Ethics, 121(3), 451-466.

Pires, S. R. (2015). The current state of supply chain management in Brazil. In Supply chain design and management for emerging markets (pp. 39-63). Springer International Publishing.

Sarkis, J. (2012). Models for compassionate operations. International Journal of Production Economics, 139(2), 359-365.

Scheer, L. K., Kumar, N., \& Steenkamp, J. B. E. (2003). Reactions to perceived inequity in US and Dutch interorganizational relationships. Academy of Management Journal, 46(3), 303-316.

Scherlen, A., \& Robinson, M. (2008). Open access to criminal justice scholarship: A matter of social justice. Journal of Criminal Justice Education, 19(1), 54-74. 
Segovia-San-Juan, A. I., Saavedra, I., \& Fernández-de-Tejada, V. (2015). Analyzing disability in socially responsible companies. Social Indicators Research, 1-29.

Sun, S.-Y., Chao, P.-J. \& Wu, C.-Y. (2009). A study on the satisfaction of supply chain management system from the view of justice and value. In Proceedings of the international conference on electronic business (ICEB), pp. 864-874.

Thürer, M., Godinho Filho, M., Stevenson, M., \& Fredendall, L. D. (2013). Competitive priorities of small manufacturers in Brazil. Industrial Management \& Data Systems, 113(6), 856-874.

Touboulic, A., \& Walker, H. (2015). Theories in sustainable supply chain management: A structured literature review. International Journal of Physical Distribution \& Logistics Management, 45(1/2), 16-42.

Ueltschy, L. C., Ueltschy, M. L., \& Fachinelli, A. C. (2007). The impact of culture on the generation of trust in global supply chain relationships. Marketing Management Journal, 17(1), 15-26.

Walker, P. H., Seuring, P. S., Sarkis, P. J., \& Klassen, P. R. (2014). Sustainable operations management: Recent trends and future directions. International Journal of Operations \& Production Management, 34(5), 1-4. 